\title{
Squamous Cell Carcinoma in Hidradenitis Suppurativa Lesions Following Tumor Necrosis Factor $\alpha$ Inhibitors
}

Shaun D. Cooper, MD; Molly C.E. Cowdrey, MD; Konstantinos D. Linos, MD; Joel A. Lefferts, PhD; Katherina K. Basic, MD

\section{PRACTICE POINTS}

- Consider biopsy of representative lesions in men older than 20 years with moderate to severe disease of the groin and/or buttocks prior to initiation of tumor necrosis factor inhibitors.

- Consider more frequent clinical monitoring with a decrease in threshold to perform biopsy of any new or ulcerating lesions.

To the Editor:

Hidradenitis suppurativa (HS) is a chronic inflammatory skin condition with high morbidity rates. Symptoms typically develop between puberty and the third decade of life, affecting twice as many females as males, with an overall disease prevalence of $1 \%$ to $4 \% .{ }^{1}$ The pathogenesis is theorized to be related to an immune response to follicular occlusion and rupture in genetically susceptible individuals.

Among the complications associated with HS, the development of cutaneous squamous cell carcinoma (SCC) is 4.6-times more likely within HS lesions than in normal skin and typically is seen in the setting of longstanding disease, particularly in men with HS lesions located on the buttocks and genital region for more than 20 years. ${ }^{2}$ In 2015, the tumor necrosis factor (TNF) inhibitor adalimumab was approved by the US Food and Drug Administration for the treatment of HS. Tumor necrosis factor $\alpha$ inhibitors have been associated with an increased risk for skin cancer in other clinical settings. ${ }^{3,4}$ We present a case of locally advanced SCC that developed in a patient with HS who was treated with adalimumab and infliximab (both TNF- $\alpha$ inhibitors), ultimately leading to the patient's death.

A 59-year-old man who smoked with a 40-year history of severe HS, who previously was lost to follow-up, presented to our dermatology clinic with lesions on the buttocks. Physical examination demonstrated confluent, indurated, boggy plaques; scattered sinus tracts with purulent drainage; scattered cystlike nodules; and tenderness to palpation consistent with Hurley stage III disease (Figure 1A). No involvement of the axillae or groin was noted. He was started on doxycycline and a prednisone taper with minimal improvement and subsequently was switched to adalimumab 3 months later. Adalimumab provided little relief and was discontinued; therapy was transitioned to infliximab 3 months later.

The patient returned to our clinic 3 months later with a severe flare and intractable pain after 4 infusions of infliximab. Physical examination showed a $7 \times 5-\mathrm{cm}$ deep

Dr. Cooper is from the Geisel School of Medicine, Dartmouth College, Hanover, New Hampshire. Drs. Cowdrey, Linos, and Lefferts are from the Dartmouth-Hitchcock Medical Center, Lebanon, New Hampshire. Dr. Cowdrey is from the Section of Dermatology, and Drs. Linos and Lefferts are from the Department of Pathology and Laboratory Medicine, Dermatopathology Division. Dr. Basic is from the James A. Haley Veterans Hospital, Tampa, and the Department of Dermatology, Morsani College of Medicine, University of South Florida, Tampa.

The authors report no conflict of interest.

Correspondence: Katherina K. Basic, MD, Department of Dermatology, 12901 Bruce B Downs Blvd, Tampa, FL 33612 (katherina.basic@va.gov). doi:10.12788/cutis.0233 

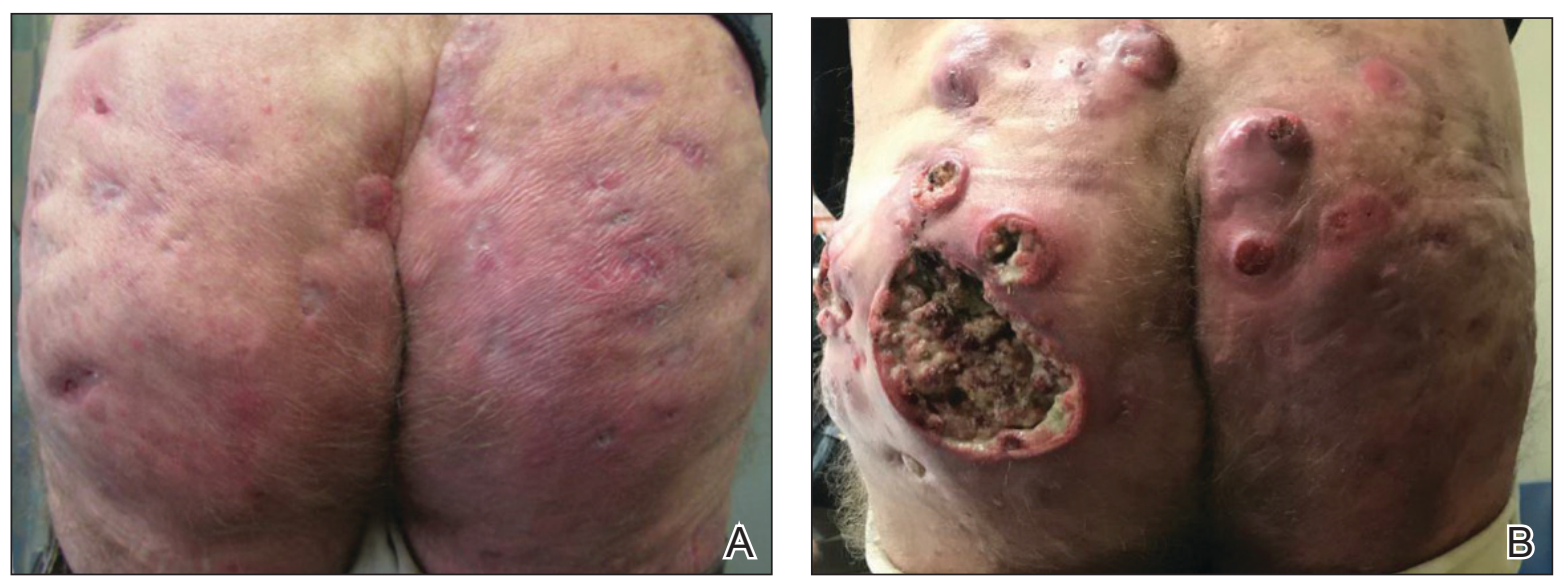

FIGURE 1. Hidradenitis suppurativa with squamous cell carcinoma (SCC) transformation. A, Three months prior to initiation of tumor necrosis factor (TNF) $\alpha$ antagonist therapy, clinical examination showed Hurley stage III disease. B, Five months after initiation of TNF- $\alpha$ antagonist therapy, deep ulceration and indurated nodules of the left buttock were present, consistent with SCC.

malodorous ulcer with fibrinous exudate on the left buttock, several 2- to $3-\mathrm{cm}$ shallow ulcers draining yellow exudate, and numerous fluctuant subcutaneous nodules on a background of scarring and sinus tracts. He was started again on doxycycline and a prednisone taper. At follow-up 2 weeks later, the largest ulcer had increased to $8 \mathrm{~cm}$, and more indurated and tender subcutaneous nodules and scattered ulcerations developed (Figure 1B). Two punch biopsies of the left buttock revealed an invasive keratinizing carcinoma with no connection to the epidermis, consistent with SCC (Figure 2). Human papillomavirus (HPV) test results with probes for $37 \mathrm{HPV}$ types-13 that were high risk (HPV-16, -18, $-31,-33,-35,-39,-45,-51,-52,-56,-58,-59$, -68)-were negative. Computerized tomography demonstrated diffuse thickening of the skin on the buttocks, inguinal adenopathy suspicious for nodal metastases, and no evidence of distant metastatic disease. Given the extent of the disease, surgical treatment was not an option, and he began receiving palliative radiotherapy. However, his health declined, and he developed aspiration pneumonia and hypotension requiring pressor support. He was transitioned to hospice care and died 3 months after presentation.

Tumor necrosis factor $\alpha$ antagonist treatment is being increasingly used to control HS but also may increase the risk for SCC development. We performed a search of PubMed articles indexed for MEDLINE as well as Web of Science using the terms hidradenitis suppurativa or acne inversa and one of the following-tumor necrosis factor inhibitor, infliximab, adalimumab, or etanercept-and squamous cell carcinoma or Marjolin ulcer. Seven cases of SCC arising in an HS patient treated with a TNF- $\alpha$ inhibitor have been reported (Table). ${ }^{5-10}$ Four cases were associated with infliximab use, 2 with adalimumab, and our case occurred after both adalimumab and infliximab treatment. All individuals were men with severe,

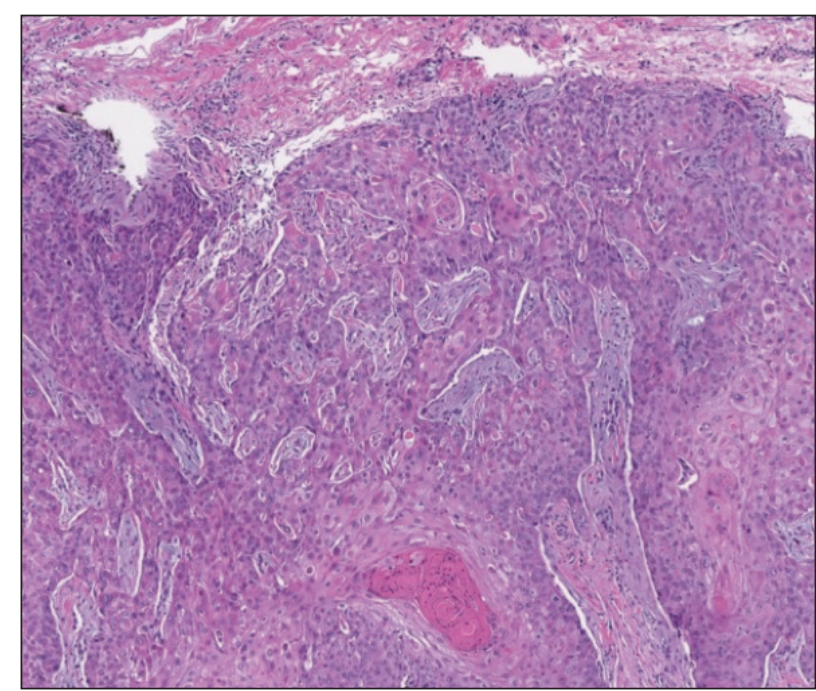

FIGURE 2. Biopsy results showed an infiltrating keratinizing carcinoma consistent with moderately differentiated squamous cell carcinoma (H\&E, original magnification $\times 100$ ).

long-standing disease of the anogenital region. In addition to smoking, HPV-16 positivity also has been reported as a risk factor for developing SCC in the setting of HS. ${ }^{11}$ In our patient, however, HPV testing did not cover all HPV strains, but several high-risk strains, including HPV-16, were negative.

Hidradenitis suppurativa is caused by an immune response to ruptured follicles and TNF- $\alpha$ antagonists are useful in suppressing this response; however, immunosuppression can lead to an increased susceptibility to malignancy, especially in SCC. It is unclear whether the use of infliximab or adalimumab is causal, additive, or a confounder in the development of SCC in patients with severe HS. It is possible that these agents increase 


\section{Reported Cases of SCC Arising in HS Following TNF- $\alpha$ Antagonist Therapy}

\begin{tabular}{|c|c|c|c|c|c|c|c|c|c|}
\hline $\begin{array}{l}\text { Reference } \\
\text { (year) }\end{array}$ & $\begin{array}{l}\text { Age, } \\
y\end{array}$ & Sex & $\begin{array}{l}\text { History } \\
\text { of HS, y }\end{array}$ & Location & $\begin{array}{l}\text { HPV } \\
\text { status }\end{array}$ & Smoker & Therapy & $\begin{array}{l}\text { Time to } \\
\text { diagnosis }^{a} \text {, } \\
\text { mo }\end{array}$ & Outcome $^{b}$ \\
\hline $\begin{array}{l}\text { Maalouf et } \mathrm{al}^{5} \\
(2006)\end{array}$ & 50 & $\mathrm{M}$ & 20 & Buttocks & NA & No & Infliximab & 5 & $\begin{array}{l}\text { Died at } \\
12 \mathrm{mo}\end{array}$ \\
\hline $\begin{array}{l}\text { Kurokawa et } a^{6} \\
\text { (2007) }\end{array}$ & 50 & $\mathrm{M}$ & 30 & Buttocks & NA & NA & Infliximab & $<6$ & $\begin{array}{l}\text { Died at } \\
<6 \mathrm{mo}\end{array}$ \\
\hline $\begin{array}{l}\text { Scheinfeld }{ }^{7} \\
(2014)\end{array}$ & 47 & $\mathrm{M}$ & $>30$ & $\begin{array}{l}\text { Groin, } \\
\text { buttocks }\end{array}$ & NA & No & Infliximab & $<1$ & $\begin{array}{l}\text { Died at } \\
11 \mathrm{mo}\end{array}$ \\
\hline $\begin{array}{l}\text { Verdelli et } \mathrm{al}^{8} \\
(2016)\end{array}$ & 25 & $\mathrm{M}$ & 25 & Buttocks & NA & Yes & Infliximab & & $\begin{array}{l}\text { Died at } \\
14 \mathrm{mo}\end{array}$ \\
\hline $\begin{array}{l}\text { Giesey et } \mathrm{al}^{9} \\
(2017)\end{array}$ & 48 & $\mathrm{M}$ & $15-20$ & $\begin{array}{l}\text { Groin, } \\
\text { buttocks }\end{array}$ & Negative & No & & & Still living \\
\hline $\begin{array}{l}\text { Roy et } \mathrm{al}^{10} \\
(2019)\end{array}$ & 64 & $\mathrm{M}$ & 28 & $\begin{array}{l}\text { Buttocks, } \\
\text { axillae }\end{array}$ & NA & NA & Adalimumab & 24 & Died \\
\hline Current report & 59 & $\mathrm{M}$ & 40 & Buttocks & Negative & & $\begin{array}{l}\text { Infliximab, } \\
\text { adalimumab }\end{array}$ & 5 & $\begin{array}{l}\text { Died at } \\
9 \mathrm{mo}\end{array}$ \\
\hline \multicolumn{10}{|c|}{ Abbreviations: SCC, squamous cell carcinoma; HS, hidradenitis suppurativa; TNF, tumor necrosis factor; HPV, human papillomavirus; } \\
\hline
\end{tabular}

the rapidity of the development of SCC in alreadysusceptible patients. Although TNF- $\alpha$ antagonists can be an effective therapeutic option for patients with moderate to severe HS, the potential risk for contributing to skin cancer development should raise provider suspicion in high-risk patients. Given the findings in this report, it may be suitable for providers to consider a biopsy prior to initiating TNF- $\alpha$ therapy in men older than 20 years with moderate to severe HS of the groin or buttocks, in addition to more frequent monitoring and a lower threshold to biopsy lesions with rapid growth or ulceration.

\section{REFERENCES}

1. Alikhan A, Lynch PJ, Eisen DB. Hidradenitis suppurativa: a comprehensive review. J Am Acad Dermatol. 2009;60:539-561; quiz 562-533.

2. Lapins J, Ye W, Nyren O, et al. Incidence of cancer among patients with hidradenitis suppurativa. Arch Dermatol. 2001;137:730-734.

3. Askling J, Fahrbach K, Nordstrom B, et al. Cancer risk with tumor necrosis factor alpha (TNF) inhibitors: meta-analysis of randomized controlled trials of adalimumab, etanercept, and infliximab using patient level data. Pharmacoepidemiol Drug Saf. 2011;20:119-130
4. Mariette X, Matucci-Cerinic M, Pavelka K, et al. Malignancies associated with tumour necrosis factor inhibitors in registries and prospective observational studies: a systematic review and meta-analysis. Ann Rheum Dis. 2011;70:1895-1904.

5. Maalouf E, Faye O, Poli F, et al. Fatal epidermoid carcinoma in hidradenitis suppurativa following treatment with infliximab. Ann Dermatol Venereol. 2006;133(5 pt 1):473-474.

6. Kurokawa I, Nishimura K, Yamanaka K, et al. Cytokeratin expression in squamous cell carcinoma arising from hidradenitis suppurativa (acne inversa). J Cutan Pathol. 2007;34:675-678.

7. Scheinfeld N. A case of a patient with stage III familial hidradenitis suppurativa treated with 3 courses of infliximab and died of metastatic squamous cell carcinoma. Dermatol Online J. 2014;20(3).

8. Verdelli A, Antiga E, Bonciani D, et al. A fatal case of hidradenitis suppurativa associated with sepsis and squamous cell carcinoma. Int J Dermatol. 2016;55:E52-E53.

9. Giesey R, Delost GR, Honaker J, et al. Metastatic squamous cell carcinoma in a patient treated with adalimumab for hidradenitis suppurativa. JAAD Case Rep. 2017;3:489-491.

10. Roy C, Roy S, Ghazawi F, et al. Cutaneous squamous cell carcinoma arising in hidradenitis suppurativa: a case report. SAGE Open Med Case Rep. 2019;7:2050313X19847359.

11. Lavogiez C, Delaporte E, Darras-Vercambre S, et al. Clinicopathological study of 13 cases of squamous cell carcinoma complicating hidradenitis suppurativa. Dermatology. 2010;220:147-153. 